\title{
Barriers for Early Detection of Cancer Amongst Urban Indian Women: A Cross Sectional Study
}

\author{
Yugantara R. Kadam, ${ }^{1, *}$ Sanjay R. Quraishi, ${ }^{1}$ Randheer V. Dhoble, ${ }^{1}$ Minaxi R. Sawant, and \\ Alka D. Gore ${ }^{1}$ \\ ${ }^{1}$ Department of Community Medicine, Bharati Vidyapeeth Deemed University Medical College, Sangli, India \\ ${ }^{*}$ Corresponding author: Yugantara R. Kadam, Department of Community Medicine, Bharati Vidyapeeth Deemed University Medical College, Sangli, India. Tel: +91-9890941745, \\ E-mail: yugakadam2011@rediffmail.com; Yugakadam2011@gmail.com
}

Received 2015 September 10; Revised 2015 October 5; Accepted 2016 January 17.

\begin{abstract}
Background: Cancer is a leading cause of death globally. Every year, millions of cancer patients could be saved from premature death and and suffering if they had timely access to early detection and treatment. There are two main components of early detection: early diagnosis and screening. In India, cancers of cervix, breast, mouth/oropharynx are the most frequent cancers in women. These cancers are amenable to early detection. More than two third of the cancer patients are already in an advanced and incurable stage at the time of diagnosis.

Objectives: This study was designed with the aim to know the reasons for non availment of cancer screening procedures and early diagnostic facilities.

Materials and Methods: This cross-sectional study was planned in Sangli, Miraj and Kupwad Corporation area during October 2013 March 2014 by a pretested questionnaire. Women of 25 years and above were study subjects selected randomly from a cluster sample of ward with estimated sample size of 559 women. Statistical analysis was done with the help of IBM SPSS 22.

Results: Nearly 74\% of women said that cancer is curable. For awareness about signs and symptoms, risk factors and screening test $82.3 \%$ women scored less than 50\% of total score. Only $17.7 \%$ women had awareness score more than 50\%. But their attitude score was $>50 \%$ in $85.2 \%$ of women. For practice score, $24.4 \%$ women scored $>50 \%$. Significant association was found between awareness, attitude and practice scores and education, occupation and history of cancer in family, friends and neighborhood of respondents.

Conclusions: Low awareness is the main barrier for undergoing cancer screening and early detection. There is a need of effective health education programme.
\end{abstract}

Keywords: Early Detection of Cancer, Screening, Awareness, Attitude, Practice

\section{Background}

Cancer is a leading cause of death globally (1). Every year, millions of cancer patients could be saved from premature death and suffering if they had timely access to early detection and treatment. There are two main components of early detection: early diagnosis and screening (1).

In India cancers of cervix, breast, mouth/oropharynx are the most frequent cancers in women (2). These cancers are amenable to early detection. More than two third of the cancer patients are already in an advanced and incurable stage at the time of diagnosis (3). Screening facility like Pap smear is available at both government and private hospitals while breast self examination can be done by women themselves if they know about it. In spite of that 'IARC screening group' mentions that health care providers in developing countries regularly see women with advanced, incurable cervical cancer (4). In a study by Bodapati and Babu conducted in Hydrabad on oncologists, it was stated that according to oncologists, late presentation of breast cancer cases was the most important cause of decreased survival among women. Most women present at stages 3 and 4 when there is no opportunity for surgical intervention (5). India has always been cited as a country with the highest incidence of oral cancers in the world. In India alone, over 100000 cases are registered every year (6). Oral cancer remains a lethal disease for over $50 \%$ of cases diagnosed annually due to the fact that most cases are in advanced stages at the time of detection despite easy accessibility of the oral cavity for regular examination (6).

\section{Objectives}

This study was aimed to interact with urban Indian women to know the barriers for early detection of cancers and non utilisation of screening procedures, and early diagnostic facilities.

Copyright (C) 2016, Iranian Journal of Cancer Prevention. This is an open-access article distributed under the terms of the Creative Commons Attribution-NonCommercial 4.0 International License (http://creativecommons.org/licenses/by-nc/4.0/) which permits copy and redistribute the material just in noncommercial usages, provided the original work is properly cited. 
Kadam YR et al.

\section{Materials and Methods}

This cross-sectional study was conducted in Sangli, Miraj and Kupwad corporation area. Women of 25 years and above were the study subjects. Calculated sample size was 510 women $\left(\mathrm{P}=83.99 \%, a=1 \%, \mathrm{~d}=5 \%, \mathrm{n}=\mathrm{z}^{2} \mathrm{pq} /\right.$ $\mathrm{d}^{2} \mathrm{p}^{2}$ two tailed) (7). A ward was selected randomly from the Sangli, Miraj and Kupwad corporation area. After random selection of ward, a house was selected randomly for identifying the study subject. Data was collected in sequence untill calculated sample size was completed. A semi-structured questionnaire suitable for the study was developed with the help of experts and a review of literature. It was peer reviewed and translated in Marathi. This questionnaire was pretested and modified accordingly. This questionnaire was used for data collection. Approval from institutional ethical committee (IEC) was obtained. A home to home visit was paid. Study subjects were explained appropriately before providing the questionnaire. Illiterate women were helped in using the questionnaire. Data collection was done by the investigator and female interns, who were trained for this purpose. A lady volunteer was used to supervise data collection to take care of bias. Women who were not willing to participate were excluded. Data was collected from July 2013 to October 2013.

Data was inserted in and analyzed by using statistical software statistical package for social sciences (SPSS; trial version 19). Percentages were calculated for awareness, attitude and practice. To study the association of sociodemographic factors with awareness, attitude and practice score was calculated for each one of them. Out of 31 questions, 24 were about awareness, three for attitude and four for practice. Maximum total score for awareness was 47 as some questions had multiple correct answers, 2 for attitude, and 4 for practice. On the basis of achieved scores, women were divided in to three equal groups. For awareness score group were: the first group: 0 -12, the second group $13-24$, and the third group 25 and above. For attitude maximum allotted score was 2 , ranging from 0 - 2. Hence three groups were made like score group with ' 0 ', with '1'and with ' 2 '. For practice, maximum allotted score was 4 . Score groups for practice were '0', '1 - 2', '3 - 4'. Then association between score groups and socio-demographic determinants like age, education, occupation, family type and history of cancer in family or neighbourhood was studied by using chi-square test.

\section{Results}

Total 559 women were studied. All women were married. Age ranged between 25 to 90 years old with a mode of 35 years old with SD 11.97. Education wise, $1.96 \%$ were illiterate. The majority, $47.22 \%$, were educated between $5^{\text {th }}$ $-12^{\text {th }}$ standard, $33.45 \%$ were graduate and $15.20 \%$ had education up to post graduate level.

By occupation, $73.16 \%$ were housewives, $4.47 \%$ self employed and $22 \%$ were in service. Most women, $56.52 \%$, were from nuclear families.

All women knew about the cancer. The majority of women, 236, (46.27\%), said that cancer is an 'unlimited growth of cells', while 249 (43.73\%) said it is 'just a lump'. Very few 32 (5.62\%) said do not know.

More than two thirds $(415,72.93 \%)$ of women said cancer can be cured while very few $(66,11.60 \%)$ said it cannot be cured. A small group (13.70\%) of women said they did not know.

Of the women who said cancer is curable, the majority (63.14\%) agreed if detected early, 4.83\% said 'right treatment for right duration is provided, while few $18.10 \%$ did not know the answer.

\subsection{Cancer of Cervix}

Majority of them $(332,59.39 \%)$ accepted that they do not know symptoms of cervical cancer, while $39.80 \%$ were aware of the symptoms. Out of total women, 164 (28.82\%) said it was irregular bleeding or spotting; $11.77 \%$ said it is red colored watery discharge and according to $6.85 \%$ post-coital bleeding was the symptom.

According to 67 (64.55\%) women cancer can be detected early, only 5.60\% disagreed and some $27.76 \%$ did not know that cancer can be detected early.

Almost 75.92\% agreed that cancer can be cured if detected early, while only $13.35 \%$ disagreed, and $8.96 \%$ did not answer. But only $44.11 \%$ women knew that detection of precancerous lesions is possible. More than half (53.60\%) were unaware. Tests for screening like Pap smear were known to $17.40 \%$, for vaginal examination $17.40 \%$, while only $5.10 \%$ were aware of colposcopy. However, the majority, 59.05\%, were not aware.

Most common reason for not undergoing screening was lack of awareness of such tests (Table 1). Of the respondents, $80.43 \%$ were willing to undergo screening tests if available, while $19.7 \%$ did not feel it is necessary. For the age of screening, majority ( $80.21 \%$ ) believed the test to be done after age of 40 years old while equal response $9.3 \%$ and $9.7 \%$ said after 30 and 35 years old respectively.

Majority of women (78.24\%) did not know the predisposing factor of cervical cancer. According to $11.3 \%$ and $10.43 \%$ women cervical cancer is common in multipara and unhygienic practices as cause of cervical cancer respectively.

Only $17.75 \%$ had undergone screening test and majority (77.5\%) not.

\subsection{Breast Cancer}

Almost half of the respondents (53.43\%) said they knew symptoms of breast cancer. Most common symptom known to them was breast lump (57.78\%) followed by changes in the skin over breast $(21.08 \%)$, discharge through nipple (13.88\%), change in the shape or site of nipple (7.02\%) and lump in axilla (2.10\%).

Majority, $76.25 \%$, had positive response regarding early detection of breast cancer. According to $66.25 \%$ of respondents, early detection leads to complete cure. Nearly 
Kadam YR et al.

$72.60 \%$ of the respondents feel that every woman should undergo screening tests for breast cancer. Women who have undergone screening at least once were only $14.60 \%$, while $83.65 \%$ have not.

Most common reason for not undergoing screening was lack of knowledge on how to perform (Table 1).

When asked of "self-examination" of breast, the majority (67.13\%) denied and $15.60 \%$ and $16.16 \%$ said yes-always and yes-occasionally respectively.

Awareness regarding the risk factors for breast cancer was like this: A) early menarche and late menopause $21.80 \%$ B) late marriage $13.53 \%$ C) late conception $16.69 \%$, D) nulliparous $16.70 \%$, E) denial for lactation $26.18 \%$, F) lactation if done less than 6 months $8.51, \mathrm{G}$ ) history of breast cancer in either mother or sister $30.75 \%$.

\subsection{Oral Cancers}

As for distribution of symptoms of oral cancer, recurrent bleeding gums: $74.24 \%$, difficulty in opening mouth: $40.98 \%$ presence of ulcer: $40.78 \%$, difficulty in swallowing: $27.59 \%$ and bad oral breathe: $27.55 \%$.

Awareness of risk factors for developing oral cancer: Tobacco chewing $74.24 \%$, ghutka chewing $75.13 \%$. Totally $26.47 \%$ were not aware.

A total of $48.14 \%$ were aware of the fact that oral cancer can occur in women too. About $40.24 \%$ were aware of the fact that oral cavity examination can identify pre-cancerous lesions. Awareness about risk factors for oral cancers: A) tobacco chewing $72.40 \%$, B) ghutka chewing $73.81 \%$, C) mishri use $60.10 \%$.

Information on history of these three cancers in relatives, friends or neighbors was collected. History of cervical cancer was present in $6.65 \%$ women, breast cancer in $15.10 \%$ and oral cancer in $8.26 \%$.

There were 91 women, who had history of cancer of cervix, 47 women cancer of breast and 37 had history of oral cancer in family or neighbors. Totally, 131 (23.43\%) women gave history of cancer in family or neighbourhood as multiple answers were given by some women.

\subsection{Awareness, Attitude and Practice Score}

Mean and SD of awareness, attitude and practice score is given in Table 2. For awareness, $82.3 \%$ women scored less than $50 \%$ of total score (Table 2 ).

Only $17.7 \%$ women had awareness score more than $50 \%$. But attitude score was $>50 \%$ in $85.2 \%$ of women. For practice score, $24.4 \%$ women scored $>50 \%$.

Significant association was found between awareness, attitude and practice scores, education, occupation and history of cancer in family, friends and neighbors of respondents. (Tables 3 - 5).

\begin{tabular}{lcc}
\hline \multicolumn{2}{l}{ Table 1. Reasons for Not Undergoing Screening ${ }^{\mathrm{a}}$} & \multicolumn{2}{l}{} & No. $(\%)$ \\
\hline Sr. No. & For Cancer of Cervix & $233(40.14)$ \\
\hline $\mathbf{1}$ & Don't know & $27(4.74)$ \\
$\mathbf{2}$ & Economic factor & $32(5.62)$ \\
$\mathbf{3}$ & Don't know the place where to do & $24(4.21)$ \\
$\mathbf{4}$ & Feel shy & $3(0.53)$ \\
$\mathbf{5}$ & Distance & $4(0.71)$ \\
$\mathbf{6}$ & Not permitted & $6(1.07)$ \\
$\mathbf{7}$ & No one to accompany & $17(3.04)$ \\
$\mathbf{8}$ & No time & $42(7.51)$ \\
\hline $\mathbf{9}$ & Fear for diagnosis &
\end{tabular}

\section{For Cancer of Breast}

\begin{tabular}{lcc}
$\mathbf{1}$ & Do not know the method & $494(86.81)$ \\
$\mathbf{2}$ & Had no privacy to perform & $24(4.21)$ \\
$\mathbf{3}$ & Fear of getting the lump & $15(2.63)$ \\
$\mathbf{4}$ & Not remembering & $14(2.46)$ \\
$\mathbf{5}$ & Lack of time & $2.98(3.11)$ \\
\hline
\end{tabular}

${ }^{\mathrm{a}}$ Multiple answers were given by respondents. 
Kadam YR et al.

\begin{tabular}{|c|c|c|c|c|c|c|c|}
\hline Statistic & Awareness Score & Frequency, \% & Attitude Score & Frequency, \% & \multicolumn{2}{|l|}{ Practice Score } & Frequency, \% \\
\hline Minimum score & 0 & $3(0.5)$ & 0 & $83(14.8)$ & \multicolumn{2}{|l|}{0} & $318(56.9)$ \\
\hline Maximum score & 44 & $1(0.2)$ & 2 & $357(63.9)$ & \multicolumn{2}{|l|}{4} & $17(3)$ \\
\hline Mean \pm SD & $15.93 \pm 6.66$ & - & $1.49 \pm 0.74$ & - & \multicolumn{2}{|l|}{$0.794 \pm 1.09$} & - \\
\hline \multirow{2}{*}{\multicolumn{2}{|c|}{ Sociodemogrphic Determinants }} & \multicolumn{3}{|c|}{ Awareness Score Group $^{a}$} & \multirow{2}{*}{ Total $^{\mathbf{a}}$} & \multirow{2}{*}{$x^{2}$} & \multirow{2}{*}{ PValue } \\
\hline & & $0-12$ & $13-24$ & 25 and Above & & & \\
\hline Age & & & & & & 6.119 & 0.19 \\
\hline Up to 35 years old & & $71(26)$ & $174(65.91)$ & $19(7.20)$ & $264(100.00)$ & & \\
\hline $36-50$ years old & & $65(30.81)$ & $123(58.29)$ & $23(10.90)$ & $211(100.00)$ & & \\
\hline$>50$ years old & & $31(36.90)$ & $45(53.57)$ & $8(9.52)$ & $84(100.00)$ & & \\
\hline Education & & & & & & 41.698 & 0 \\
\hline Illiterate and prin & & $13(56.52)$ & $8(34.78)$ & $2(8.70)$ & $23(100.00)$ & & \\
\hline Secondary and hi & secondary & $93(35.23)$ & $162(61.36)$ & $9(3.41)$ & $264(100.00)$ & & \\
\hline Graduates & & $47(25.13)$ & $119(63.64)$ & $21(11.23)$ & $187(100.00)$ & & \\
\hline Postgraduates an & fessionals & $14(16.47)$ & $53(62.35)$ & $18(21.18)$ & $85(100.00)$ & & \\
\hline Occupation & & & & & & 53.91 & 0 \\
\hline Self-employed & & $11(44.00)$ & $13(52.00)$ & $1(4.00)$ & $25(100.00)$ & & \\
\hline Housewife & & $135(33.01)$ & $255(62.35)$ & $19(4.65)$ & $409(100.00)$ & & \\
\hline Service & & $19(15.45)$ & $74(60.16)$ & $30(24.39)$ & $123(100.00)$ & & \\
\hline Type of family & & & & & & 4.436 & 0.19 \\
\hline Joint family & & $80(32.92)$ & $137(56.38)$ & $26(10.70)$ & $243(100.00)$ & & \\
\hline Nuclear family & & $87(27.53)$ & $205(64.87)$ & $24(7.59)$ & $316(100.00)$ & & \\
\hline History of cancer & & & & & & 10.924 & 0.004 \\
\hline No & & $141(32.94)$ & $255(59.58)$ & $32(7.48)$ & $428(100.00)$ & & \\
\hline Yes & & $26(19.85)$ & $87(66.41)$ & $18(13.74)$ & $131(100.00)$ & & \\
\hline Total & & $167(29.87)$ & $342(61.18)$ & $50(8.94)$ & $559(100.00)$ & & \\
\hline \multicolumn{8}{|c|}{${ }^{a}$ Values are expressed as No. (\%). } \\
\hline \multirow{3}{*}{\multicolumn{2}{|c|}{ Socio-Demogrphic Determinants }} & d Attitude Sco & & & & & \\
\hline & & \multicolumn{3}{|c|}{ Attitude Score Group ${ }^{a}$} & \multirow[t]{2}{*}{ Total $^{\mathbf{a}}$} & \multirow[t]{2}{*}{$x^{2}$} & \multirow[t]{2}{*}{ P Value } \\
\hline & & 0.00 & 1.00 & 2.00 & & & \\
\hline Age & & & & & & 2.778 & 0.596 \\
\hline Up to 35 years ol & & $37(14.02)$ & $64(24.24)$ & $163(61.74)$ & $264(100.00)$ & & \\
\hline 36 - 50 years old & & $32(15.17)$ & $39(18.48)$ & $140(66.35)$ & $211(100.00)$ & & \\
\hline$>50$ years old & & $14(16.67)$ & $16(19.05)$ & $54(64.29)$ & $84(100.00)$ & & \\
\hline Education & & & & & & 37.667 & 0.000 \\
\hline Illiterate and pri & & $10(43.48)$ & $3(13.04)$ & $10(43.48)$ & $23(100.00)$ & & \\
\hline Secondary and $\mathrm{h}$ & r secondary & $53(20.08)$ & $61(23.11)$ & $150(56.82)$ & $264(100.00)$ & & \\
\hline Graduates & & $17(9.09)$ & $39(20.86)$ & $131(70.05)$ & $187(100.00)$ & & \\
\hline Postgraduates ar & rofessionals & $3(3.53)$ & $16(18.82)$ & 66 (77.65) & $85(100.00)$ & & \\
\hline Occupation & & & & & & 14.450 & 0.006 \\
\hline Self-employed & & $7(28.00)$ & $7(28.00)$ & $11(44.00)$ & $25(100.00)$ & & \\
\hline Housewife & & $68(16.63)$ & $85(20.78)$ & $256(62.59)$ & $409(100.00)$ & & \\
\hline Service & & $7(5.69)$ & $27(21.95)$ & $89(72.36)$ & $123(100.00)$ & & \\
\hline Type of family & & & & & & 0.607 & 0.738 \\
\hline Joint family & & $37(15.23)$ & $55(22.63)$ & $151(62.14)$ & $243(100.00)$ & & \\
\hline Nuclear family & & $46(14.56)$ & $64(20.25)$ & $206(65.19)$ & $316(100.00)$ & & \\
\hline History of cancer & & & & & & 9.159 & 0.010 \\
\hline No & & $71(16.59)$ & $98(22.90)$ & $259(60.51)$ & $428(100.00)$ & & \\
\hline Yes & & $12(9.16)$ & $21(16.03)$ & $98(74.81)$ & $131(100.00)$ & & \\
\hline Total & & $83(14.85)$ & 119 (21.29) & $357(63.86)$ & $559(100.00)$ & & \\
\hline
\end{tabular}

${ }^{\mathrm{a}}$ Values are expressed as No. (\%). 
Kadam YR et al.

\begin{tabular}{|c|c|c|c|c|c|c|}
\hline \multirow[t]{2}{*}{ Socio-Demogrphic Determinants } & \multicolumn{3}{|c|}{ Practice Score Group $^{a}$} & \multirow[t]{2}{*}{ Total $^{\mathrm{a}}$} & \multirow[t]{2}{*}{$x^{2}$} & \multirow[t]{2}{*}{ P Value } \\
\hline & 'o'score & 2-Jan & 4-Mar & & & \\
\hline Age & & & & & 4.787 & 0.31 \\
\hline Up to 35 years old & $151(57.20)$ & $95(35.98)$ & $18(6.82)$ & $264(100.00)$ & & \\
\hline 36 - 50 years old & $115(54.50)$ & $71(33.65)$ & $25(11.85)$ & $211(100.00)$ & & \\
\hline$>50$ years old & $52(61.90)$ & $26(30.95)$ & $6(7.14)$ & $84(100.00)$ & & \\
\hline Education & & & & & 75.542 & 0 \\
\hline Illiterate and primary & $18(78.26)$ & $5(21.74)$ & $0(0.00)$ & $23(100.00)$ & & \\
\hline Secondary and higher secondary & $193(73.11)$ & $60(22.73)$ & $11(4.17)$ & $264(100.00)$ & & \\
\hline Graduates & $80(42.78)$ & $86(45.99)$ & $21(11.23)$ & $187(100.00)$ & & \\
\hline Postgraduates and professionals & $27(31.76)$ & $41(48.24)$ & $17(20.00)$ & $85(100.00)$ & & \\
\hline Occupation & & & & & 61.803 & 0 \\
\hline Self-employed & $21(84.00)$ & $3(12.00)$ & $1(4.00)$ & $25(100.00)$ & & \\
\hline Housewife & $262(64.06)$ & $119(29.10)$ & $28(6.85)$ & $409(100.00)$ & & \\
\hline Service & $33(26.83)$ & $70(56.91)$ & $20(16.26)$ & $123(100.00)$ & & \\
\hline Type of family & & & & & 0.209 & 0.901 \\
\hline Joint family & $140(57.61)$ & $81(33.33)$ & $22(9.05)$ & $243(100.00)$ & & \\
\hline Nuclear family & $178(56.33)$ & $111(35.13)$ & $27(8.54)$ & $316(100.00)$ & & \\
\hline History of cancer & & & & & 8.133 & 0.017 \\
\hline No & $253(59.11)$ & $145(33.88)$ & $30(7.01)$ & $428(100.00)$ & & \\
\hline Yes & $65(49.62)$ & $47(35.88)$ & $19(14.50)$ & $131(100.00)$ & & \\
\hline Total & $318(56.89)$ & $192(34.35)$ & $49(8.77)$ & $559(100.00)$ & & \\
\hline
\end{tabular}

${ }^{\mathrm{a}}$ Values are expressed as No.(\%).

\section{Discussion}

Most common cancers in Indian women are cancer of cervix, cancer of breast and oral cancers. If women knew about the risk factors, then it were possible to prevent these cancers. Cancer of cervix and oral cancers have premalignant lesions at a site which is accessible for inspection. Intervention at this stage also can prevent development of malignancy. For cancer of breast early detection of malignant lesion is possible. For all these three cancers screening tests are available which are simple, non-invasive and effective. In spite of that, women usually attend clinics with malignancy and most commonly with advanced malignancy. According to Denny et al. population based cancer registries indicate a slow but steady decline in cervical cancer incidence rates over the last two decades. The risk of disease is still high (8). In a study by Bodapati and Babu on oncologists, it is stated that most women present at stage 3 and 4 when there is no opportunity for surgical intervention. It is the most important cause of decreased survival among women (5).

One positive finding is that nearly $74 \%$ of women said that cancer is curable. Awareness about risk factors for all three cancers was low. Similar findings are mentioned by other investigators also (9-12). Awareness about symptoms was very low for cervical cancer than breast cancer and for oral cancers. Awareness about screening was the lowest for cervical cancers preceded by cancer of breast and then cancer oral cavity. Similar findings are noted by other studies conducted in rural area from same district. However, awareness about cancer of breast and oral cancer is lower than this study, but it follows the same pattern (7). So overall awareness is low for screening. Similar findings are mentioned by other studies also (13-17). Most common reasons for not undergoing screening was lack of awareness about tests. For cancer of breast, those who knew about breast self examination, forgetfulness and fear of cancer was the reason for not undergoing screening. Similar findings are mentioned by other studies (18). More than $70 \%$ respondents said that women should undergo screening. This proportion was better than the one mentioned by Aswathy et al. (i.e. only one third women were desirous of undergoing screening for cervical cancer) $(7,9)$. The reason may be the fact that both of these studies are conducted in rural areas.

Attitude score was much higher than awareness score. That means women think positively about screening. Practice score was less than attitude but better than awareness. Attitude score was better than awareness and practice scores. It indicates that poor awareness has led to poor practice. If they know about sign and symptoms 
of cancers and screening test, only then screening or early diagnosis will happen. All three scores were better in educated women and those who were in service. A study from India by Elango et al. and another from Iran by Pakfetrat et al. found an association between education and awareness $(10,12)$. History of cancer in family members, relatives or in neighbors has significantly improved not only awareness but also attitude as well as practice. Similar types of observations are noted in another study which was conducted on nurses from rural areas of Turkey (19). Similar findings are noted in a study conducted in rural area from same region (7).

In this study, education plays significant role in awareness. The higher the education level, the higher the awareness, while education changes the attitude towards the disease and increases the acceptance of cancer screening and diagnostic procedures and motivates to identify precancerous conditions and early signs and symptoms of disease.

Women show positive association with those in service for increased awareness and changing attitude towards cancer by practicing acceptance by seeking early cancer screening and diagnostic procedures. History of cancer in family, friends or neighbourhood sensitizes the women to gather the knowledge and thereby increase awareness and change the attitude by removing the fear of seeking early screening and diagnostic procedures for early cancer detection.

Education provides opportunity to women to have service or work and exposes them to direct interaction with colleagues, group discussions and printed health educational material. This leads to increased awareness changing the attitude and bringing into practice by accepting early cancer screening and diagnostic procedures.

So it is evident that 'patient delay' is due to lack of awareness about precancerous lesions, sign and symptoms of disease, and availability of diagnostic facilities is the main reason for late diagnosis of cancers. Neither the symptoms of cancer nor the main risk factors are well understood by the women under study.

\subsection{Conclusions}

Low awareness is the main barrier for undergoing cancer screening and early detection. There is a need of effective health education programme.

\section{Footnote}

Authors' Contribution:Yugantara R. Kadam: design, definition of intellectual content, literature search, data acquisition, data analysis, statistical analysis, manuscript preparation, manuscript editing, manuscript review, guarantor; Sanjay R. Quraishi: literature search, manuscript editing, manuscript preparation; Randheer V. Dhoble: literature search, data acquisition, manuscript preparation, manuscript review, manuscript editing; Minaxi R. Sawant: manuscript editing, data analysis; Alka D. Gore: manuscript review, statistical analysis, data analysis.

Financial Disclosure:None declared.

Funding/Support: None declared.

\section{References}

1. WHO. Introduction to the Cancer Control Series. Cancer Control: Knowledge in to Action, WHO Guide for Effective Programmes: Early detection, 2007. Available at : http://www.who.int/cancer/ modules/Prevention\%20Module.pdf.

2. CMR 2004 Annual Report. Available at : http://icmr.nic.in/annual/hqds2004/reproductive.pdf.

3. Park K. Cancer. Park's Textbook of Preventive and Social Medicine. 21st ed. Jabalpur: M/S Banarasidas Bhanot publishers; 2011. p. 353.

4. France: World Health Organization; Available from: http:| screening.iarc.fr.

5. Bodapati SL, Babu GR. Oncologist perspectives on breast cance screening in India- results from a qualitative study in Andhra Pradesh. Asian Pac J Cancer Prev. 2013;14(10):5817-23. [PubMed 24289583]

6. Warnakulasuriya S. Global epidemiology of oral and oropharyngeal cancer. Oral Oncol. 2009;45(4-5):309-16. doi: 10.1016/j. oraloncology.2008.06.002. [PubMed:18804401]

7. Tripathi N, Kadam YR, Dhobale RV, Gore AD. Barriers for early detection of cancer amongst Indian rural women. South Asian J Cancer 2014;3(2):122-7. doi:10.4103/2278-330X.130449. [PubMed:24818108]

8. Denny L, Quinn M, Sankaranarayanan R. Chapter 8: Screening for cervical cancer in developing countries. Vaccine. 2006;24 Suppl 3:S3/71-7. doi:10.1016/j.vaccine.2006.05.121. [PubMed: 16950020]

9. Aswathy S, Quereshi MA, Kurian B, Leelamoni K. Cervical cancer screening: Current knowledge \& practice among women in a rural population of Kerala, India. Indian J Med Res. 2012;136(2):20510. [PubMed: 22960886]

10. Elango JK, Sundaram KR, Gangadharan P, Subhas P, Peter S, Pulayath C, et al. Factors affecting oral cancer awareness in a high-risk population in India. Asian Pac J Cancer Prev. 2009;10(4):627-30. [PubMed: 19827883]

11. Ariyawardana A, Vithanaarachchi N. Awareness of oral cancer and precancer among patients attending a hospital in Sri Lanka. Asian Pac J Cancer Prev. 2005;6(1):58-61. [PubMed: 15780034]

12. Pakfetrat A, Falaki F, Esmaily HO, Shabestari S. Oral cancer knowledge among patients referred to Mashhad Dental School, Iran Arch Iran Med. 2010;13(6):543-8. [PubMed:21039012]

13. Sandeep S. Factors influencing uptake of cervical cancer screening among women in India: A hospital based pilot study. J Community Med Health Educ. 2012;2:2-6.

14. Modeste NN, Caleb-Drayton VL, Montgomery S. Barriers to early detection of breast cancer among women in a Caribbean population. Rev Panam Salud Publica. 1999;5(3):152-6. [PubMed: 10355312]

15. Cunningham MS, Skrastins E, Fitzpatrick R, Jindal P, Oneko O Yeates K, et al. Cervical cancer screening and HPV vaccine acceptability among rural and urban women in Kilimanjaro Region, Tanzania. BMJ Open. 2015;5(3):e005828. doi: 10.1136/bmjopen-2014-005828. [PubMed:25757944]

16. Marlow LA, Waller J, Wardle J. Barriers to cervical cancer screening among ethnic minority women: a qualitative study. J Fam Plann Reprod Health Care. 2015;41(4):248-54. doi: 10.1136/jfprhc-2014-101082. [PubMed: 25583124]

17. Abotchie PN, Shokar NK. Cervical cancer screening among college students in ghana: knowledge and health beliefs. Int J Gy necol Cancer. 2009;19(3):412-6. doi: 10.1111/IGC.0b013e3181a1d6de. [PubMed: 19407569]

18. Rao RS, Nair S, Nair NS, Kamath VG. Acceptability and effectiveness of a breast health awareness programme for rural women in India. Indian J Med Sci. 2005;59(9):398-402. [PubMed:16199925

19. Ertem G. Awareness of cervical cancer risk factors and screening behaviour among nurses in a rural region of Turkey. Asian Pac J Cancer Prev. 2009;10(5):735-8. [PubMed:20104960] 